\title{
Computational Wind Engineering of a Mast-supported Tensile Structure
}

\author{
Sherly Joanna Pool Blanco ${ }^{*}$, Krisztián Hincz $^{1}$ \\ ${ }^{1}$ Department of Structural Mechanics, Faculty of Civil Engineering, Budapest University of Technology and Economics, H-1521 Budapest, \\ P.O.B. 91, Hungary \\ * Corresponding author, e-mail: sherlyjoannapoolblanco@edu.bme.hu
}

Received: 27 May 2021, Accepted: 15 October 2021, Published online: 05 November 2021

\begin{abstract}
The Computational Fluid Dynamics (CFD) analysis of wind actions on a cube and on the hyperbolic surface of a mast-supported tensile structure is presented. As standard in Computational Wind Engineering (CWE) the models were analyzed in incompressible fluid flow. For the CWE study, the Reynolds-Averaged Navier-Stokes (RANS) equations were solved with two of the most widely used turbulence models, Realizable $k-\varepsilon$ and SST $k-\omega$. The validation of the CWE models included the comparison of the numerically determined pressure coefficient fields with existing Wind Tunnel test (WT) results. The membrane forces and the displacements of the membrane roof were calculated by the Dynamic Relaxation Method (DRM), corresponding to the different (CWE and WT) pressure coefficient fields of the tensile roof. In addition to the pressure coefficients, the membrane force and the displacement fields and their significant values were also compared. It is presented that both turbulence models provide a suitable solution; the pressure coefficients and the membrane forces are also acceptable approaches to the experimental results.
\end{abstract}

Keywords

tensile membrane structures, Computational Wind Engineering, wind actions, pressure coefficients

\section{Introduction}

Tensile membrane structures have been increasingly applied in the last decades. They are widely used, from small tents providing shelter against rain or sun to largespan roofs over exhibition halls or stadiums. These structures with exceptional shape are composed of synthetic membrane materials, cables, supporting arches, and beams. The membrane only resists tension; its bending stiffness is negligible [1-4].

The main advantages of tensile membrane structures are their light weight, large attainable free-span, which can be covered economically without internal support, efficient transportation, and fast installation. They might be permanent, deployable, or temporary structures [5-7].

Regarding their design procedure, tensile membrane structures diverge from structures composed of conventional materials like concrete, wood, or steel. For the latter, the shape is typically determined before any structural analysis process; then internal forces and displacements are calculated. This design order cannot be applied for tensile membrane structures because their prestress forces are closely related to their equilibrium shape.
The design process of tensile membrane structures can be divided into four parts: (a) form-finding, (b) cutting pattern generation, (c) determination of the construction shape, and (d) static analysis [8]. The form-finding provides an equilibrium shape according to a specific stress distribution and the given boundary conditions. The cutting pattern contains all the 2D coordinates of the material stripes that provide the required $3 \mathrm{D}$ surface after welding and prestressing. This shape is the so-called construction shape. The most critical external forces to be considered in the structural analysis of tensile membrane structures are wind and snow. This computation is more complicated than that for conventional structures due to their unique and complex geometry [9].

The wind pressure forces on a structure are determined as a combination of several parameters like the local velocity, the structure height, topography characteristics, and pressure coefficients. The pressure coefficients are non-dimensional parameters [10]:

$$
C_{p}=\frac{p-p_{0}}{\frac{1}{2} \rho U^{2}},
$$


where:

$p \quad$ is the pressure in a specific point on the surface,

$p_{0} \quad$ is the far upstream pressure,

$U$ is the free-stream velocity,

$\rho \quad$ is the fluid density.

Design codes provide $C_{p}$ values for structures with simple shapes; but not for the hyperbolic surfaces of tensile membrane structures. For the wind analysis of membrane structures, it is recommended to carry out Wind Tunnel experiments or apply available experimental data about structures with similar geometry [11]. Wind tunnel tests provide precise results, but they are expensive and time-consuming. It also has to be mentioned that for the determination of $C_{p}$ values, using aeroelastic models is highly complicated; therefore, only rigid models are used despite the large displacements of tensile structures $[9,12]$. The effect of the large displacements of a membrane structure on the pressure coefficients was analyzed in [4].

Nowadays, WT measurements are more and more often replaced by Computational Fluid Dynamics (CFD), which is an engineering tool to describe fluid flows numerically. Computational Wind Engineering (CWE) is a CFD subfield aimed to describe the wind effects on buildings. Compared to WT experiments, CWE has advantages: lower initial and maintenance costs, less restrictive model scale limitations, and potential to solve multi-physics problems [10]. Some research in CWE simulations and WT experiments of membrane structures are introduced briefly in the following paragraphs.

Gamboa-Marrufo et al. [9] obtained experimental pressure coefficients of an arch-supported tensile roof. The experiments were developed in an open subsonic wind tunnel with laminar flow by constant velocities of 20 and $25 \mathrm{~m} / \mathrm{s}$. The analyzed wind directions, measured from the plane of the supporting arch, were $0^{\circ}, 90^{\circ}$, and $45^{\circ}$. The maximum positive (0.40) and maximum negative (-1.50) pressure coefficients were equally detected in the case of $45^{\circ}$ wind direction. The pressure coefficient fields were presented in detail for all analyzed wind directions.

The CWE analysis of the membrane structure mentioned above was introduced in [12]. ANSYS-Fluent with a constant velocity equal to $10 \mathrm{~m} / \mathrm{s}$ was applied at the inlet of the analyzed domain. The pressure coefficients were determined based on $k-\varepsilon$ turbulence model. The mean difference between WT and CWE $C_{p}$ values was around $10 \%$.

Sun et al. [13] determined wind pressure forces over an oval-shaped arch-supported membrane structure by WT experiments. Closed and open structures (with and without sidewalls) were analyzed. Furthermore, different rise-tospan ratios, wind directions, and terrain categories were considered for both cases. According to their results, the influence of wind direction, rise-to-span ratio, and terrain category are more significant on the windward area than on the leeward side for both closed and open structures.

WT experiments in line with CWE simulations can lead to a better understanding and more precise analysis of tensile membrane structures.

The aim of the current research was to validate and compare CWE calculations based on different turbulence models. In the first step, a cube was analyzed, because of the relatively large number of available experimental and numerical results to compare. In the second step, a mast-supported membrane structure was examined. The $C_{p}$ values were calculated on the basis of different turbulence models and compared with experimental results of the same structure. Since in the case of the design of membrane structures the membrane forces are the most important variables, the membrane force distribution was determined according to different $C_{p}$ fields.

\section{Computational Wind Engineering (CWE)}

CWE only considers incompressible flow. The fluid flow behavior is described by the equation of continuity (Eq. (2)) and the Navier-Stokes equations (Eq. (3)) (using Einstein notation):

$$
\begin{aligned}
& \frac{\partial U_{i}}{\partial x_{i}}=0, \\
& \frac{\partial U_{i}}{\partial t}+U_{j} \frac{\partial U_{i}}{\partial x_{j}}=-\frac{1}{\rho} \frac{\partial p}{\partial x_{i}}+v \frac{\partial^{2} U_{i}}{\partial x_{j} \partial x_{j}}+f_{i},
\end{aligned}
$$

where:

$U_{i} \quad$ are the velocity components in the directions in a Cartesian coordinate system $(i=1,2,3)$,

$p$ is the pressure,

$v \quad$ is the fluid kinematic viscosity,

$f_{i} \quad$ is the vector representing body forces.

There are different solution strategies for the simulation of turbulence motions in the flow from the most precise Direct Numerical Simulation (DNS), where all eddy motions are resolved, to the Reynolds-Averaged Navier-Stokes Simulation (RANS) where all eddy motions are modelled. Since the simulation cost of the DNS is extremely high, it is not applied for practical CWE problems. There are several methods between the two extremes, for example in the case of Large Eddy Simulation (LES) the larger eddies are resolved, but the smaller ones are modelled [10]. 
In the current research RANS was applied because of its relatively low computational cost. Among several available turbulence models, the Realizable $k-\varepsilon$ and the SST $k-\omega$ model were selected for the analysis.

\section{CWE analysis of a cube}

As a first step of validating the applied CWE technique and comparing the different turbulence models, a cube was analyzed. Many authors have deeply studied the flow around a cube, providing WT and $\mathrm{CWE} C_{p}$ values in the literature.

Richards et al. [14] obtained wind pressures on a $6 \mathrm{~m}$ cube immersed in the Atmospheric Boundary Layer (ABL). First, the pressure was measured on the surface of a full-scale cube located in an "open-country" at the Silsoe Research Institute, UK. Later, they carried out WT experiments also on a scaled model [15-16]. Castro and Robins [17] completed the WT experiments of a $20 \mathrm{~cm}$ cube immersed in uniform, and boundary layer upstream flows. Irtaza et al. [18] compared the results based on the full-scale, so-called Silsoe cube, WT tests and CWE calculations. Amaya-Gallardo et al. [19] analyzed the wind pressures on $20 \mathrm{~cm}$ and $40 \mathrm{~cm}$ cubes immersed in boundary layer flow; their studies were based on WT tests and CWE.

In the current research, the CWE analysis of the full-scale $6 \mathrm{~m}$ cube was carried out. The domain sizes were established according to [20], $30 \mathrm{~m}$ between the cube front face and the inlet of the domain, $30 \mathrm{~m}$ between cube side parallel with the wind and the lateral boundary, $30 \mathrm{~m}$ between the top of the cube and the top of the domain, and $90 \mathrm{~m}$ between the leeward side of the cube and the outlet of the domain. Because of symmetry, only half of the cube was considered.

The inlet wind velocity profile was given by the powerlaw equation:

$$
U / U_{h}=\left(Z / Z_{h}\right)^{\alpha}
$$

where:

$U \quad$ is the velocity given at a specific point,

$Z \quad$ is the height in a specific point,

$U_{h} \quad$ is the velocity at certain reference height,

$\alpha \quad$ is the velocity exponent which depends on the

terrain roughness,

$Z_{h} \quad$ is the reference height.

Based on ASCE 7 Standard [21] $\alpha$ was selected equal to $1 / 9.5$, and according to [14-16], the velocity at the cube height $(6 \mathrm{~m})$ was set to $10 \mathrm{~m} / \mathrm{s}$. The steady-state CWE analysis was completed on the basis of Realizable $k-\varepsilon$ and SST $k-\omega$ turbulence models. Different meshes were applied for the different turbulence models with approximately 1.5 million (Realizable $k-\varepsilon$ ) and 4 million (SST $k-\omega$ ) elements.

Fig. 1 shows the mesh for the Realizable $k-\varepsilon$ model. The Coupled discretization solver was used to solve the fluid equations, and the convergence criterion for the residuals was $1 \times 10^{-5}$.

ANSYS-Fluent 2019 R3 was used for the computations. The velocity profile in the symmetry plane based on the Realizable $k-\varepsilon$ model is presented in Fig. 2.

Fig. 3 depicts experimental and CFD-based pressure coefficients for both full-size and scaled models along the centerline in the vertical plane parallel to the wind direction (a), and along the cube horizontal centerline (b).

The largest differences between the WT and CWE values (even between the different experimental results) can be detected on the top and on the side parallel with the wind.

Even though a cube represents a bluff body where the separation of the flow is located unambiguously along the cube edges, there are still some discrepancies between the results presented by different authors. Richards and Hoxey [16] concluded that roof and leeward wall pressures are sensitive to the flow conditions i.e., velocity profile, turbulence, and Reynolds number. Fig. 4 shows the distribution of the $C_{p}$ values obtained by Realizable $k-\varepsilon$ (a) and SST $k-\omega(b)$ turbulence models.

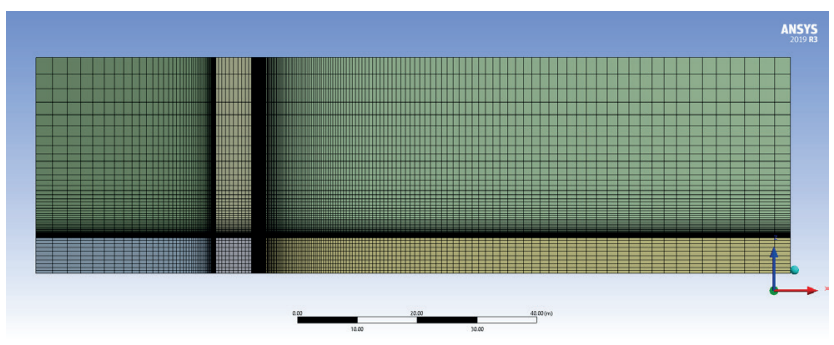

Fig. 1 Mesh for Realizable $k-\varepsilon$ turbulence model

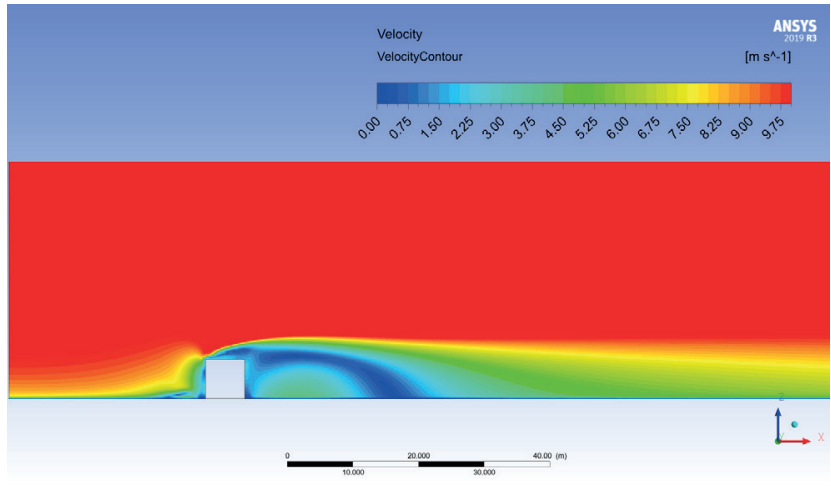

Fig. 2 Velocity contour profile in the domain symmetry plane developed by Realizable $k-\varepsilon$ turbulence model 


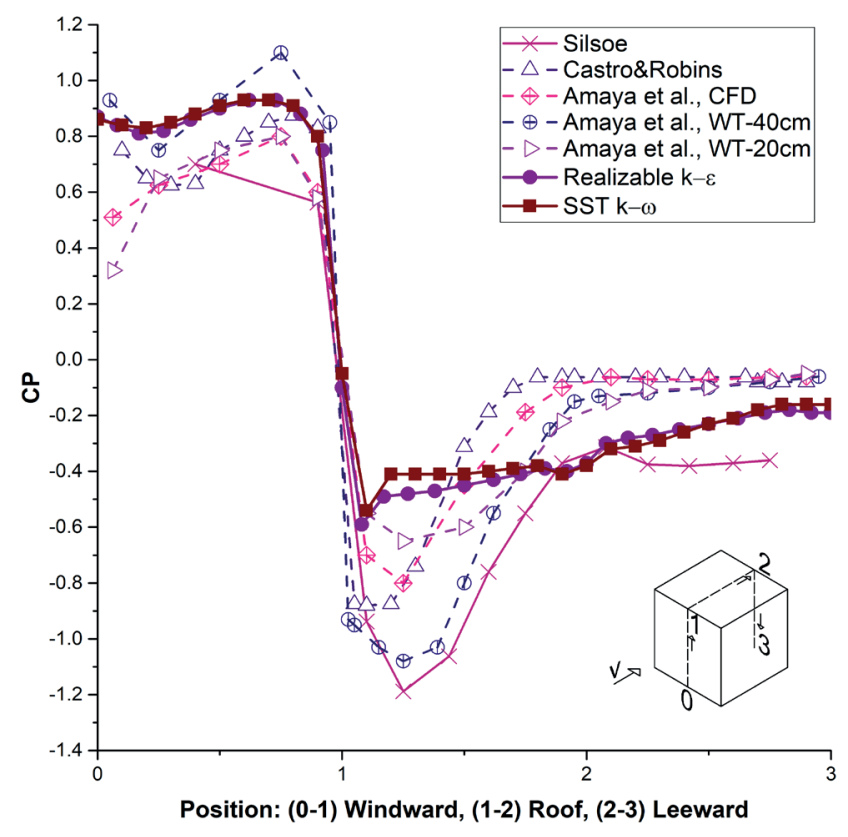

(a)

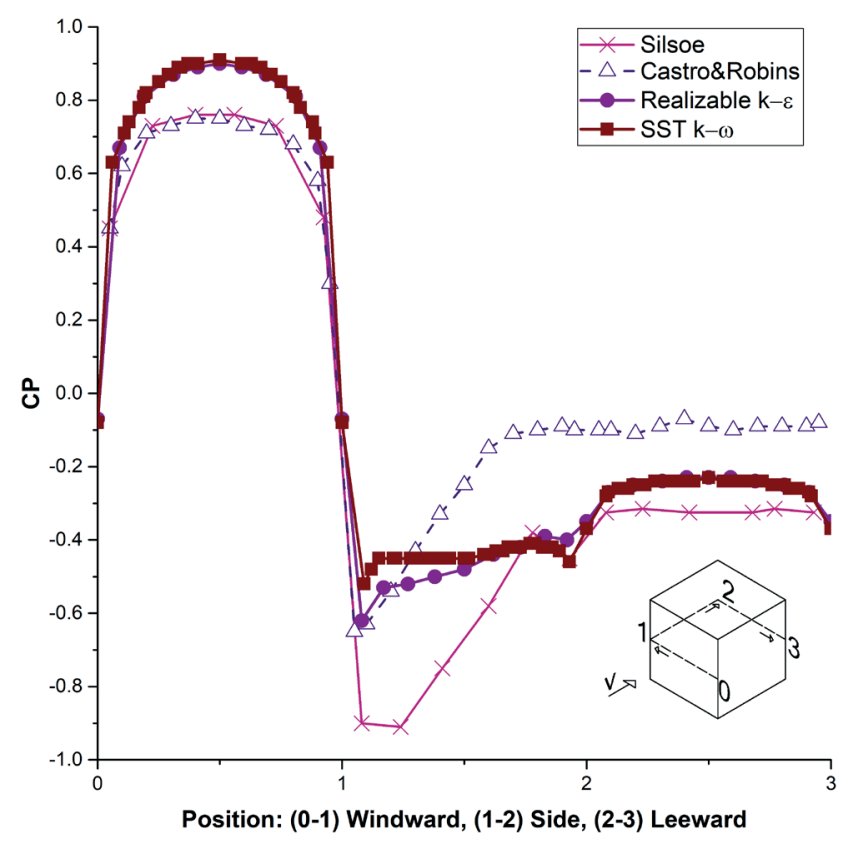

(b)

Fig. 3 Pressure coefficients on the cube based on WT and CWE results, centerline in the vertical plane parallel to wind direction (a), and along cube horizontal centerline

\section{Wind analysis of the mast-supported tensile structure} The results of the WT test of a mast-supported membrane structure were presented in [4]. During the current research, the same structure was analyzed with the tools of CWE. The fully closed tent structure is composed of three parts, the vertical walls, the hyperbolic membrane, and the closing cap on the top of the membrane. The membrane was prestressed between the edge at the

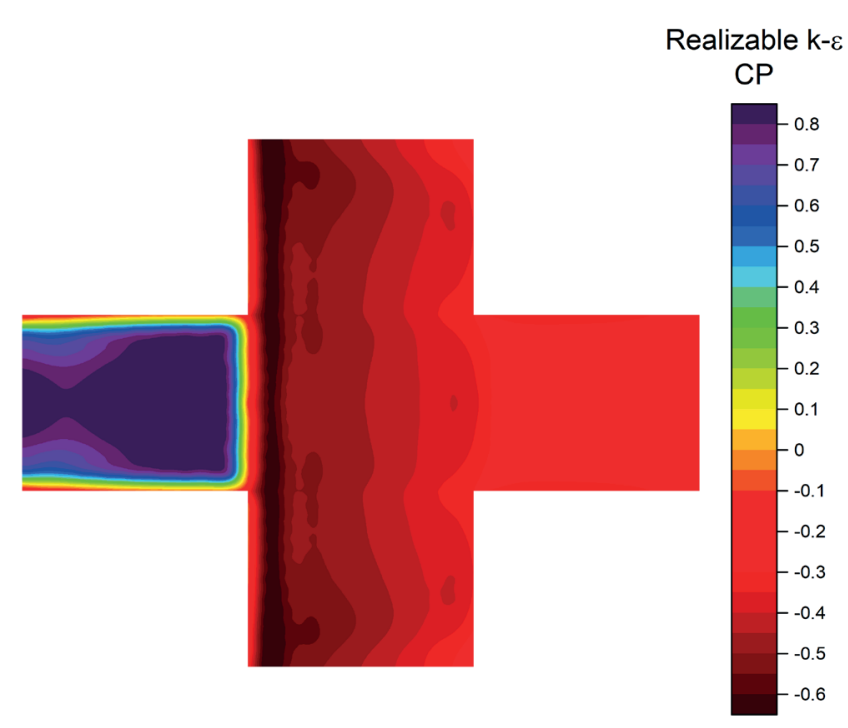

(a)

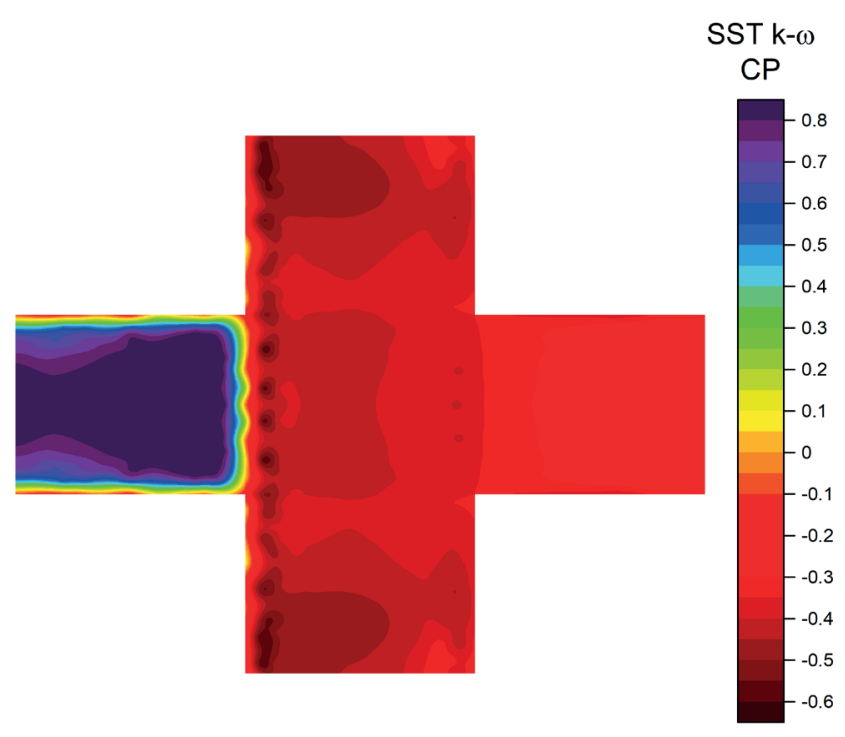

(b)

Fig. 4 Pressure coefficients on the cube surface, determined by the Realizable $k-\varepsilon$ (a), and by the SST $k-\omega$ (b) turbulence models

top of the walls and the upper fixed ring. The equilibrium shape of the prestressed membrane was determined by the DRM. The prototype structure and its dimensions are shown in Fig. 5.

\subsection{Wind tunnel test}

The experimental tests were carried out in the Wind Engineering Laboratory of the Civil Engineering Faculty of the Autonomous University of Yucatan. The wind tunnel has a testing area of $1.5 \mathrm{~m}$ length and $1 \mathrm{~m}^{2}$ cross-section. The applied scale for the rigid model was 1:30; its dimensions are presented in Table 1 . The model with the measurement holes can be seen in Fig. 6 . 

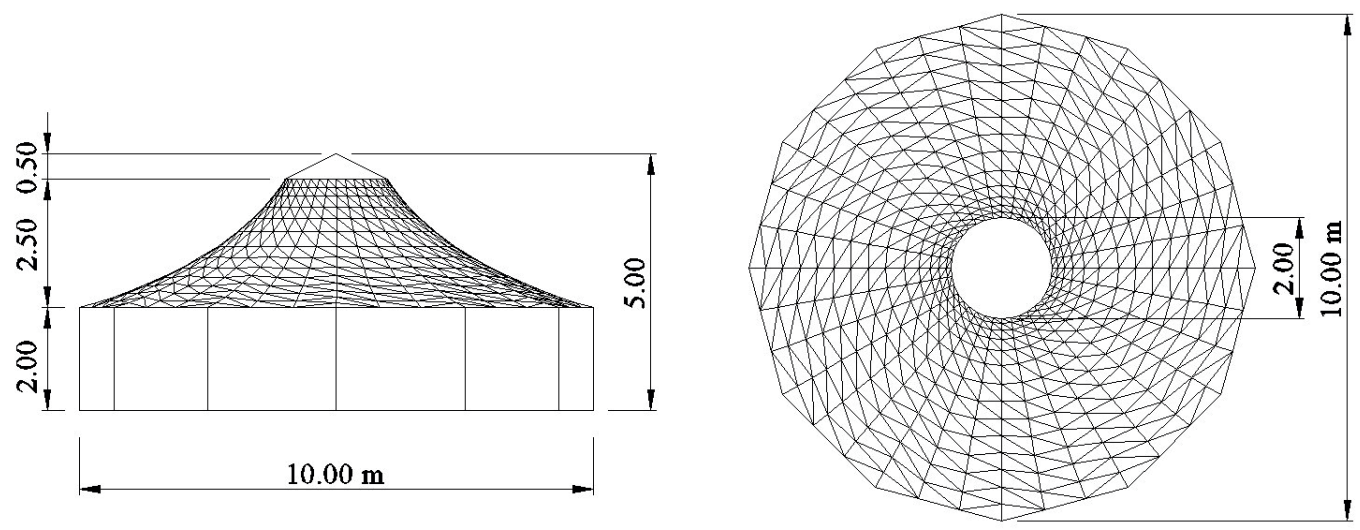

Fig. 5 Mast-supported tensile structure, front, and top view

Table 1 Prototype and model specifications

\begin{tabular}{lccc}
\hline & Along axis & Prototype & Model 1:30 \\
\hline Width & $\mathrm{X}$ & $10 \mathrm{~m}$ & $333.3 \mathrm{~mm}$ \\
Length & $\mathrm{Y}$ & $10 \mathrm{~m}$ & $333.3 \mathrm{~mm}$ \\
Height & $\mathrm{Z}$ & $5 \mathrm{~m}$ & $166.7 \mathrm{~mm}$ \\
\hline
\end{tabular}

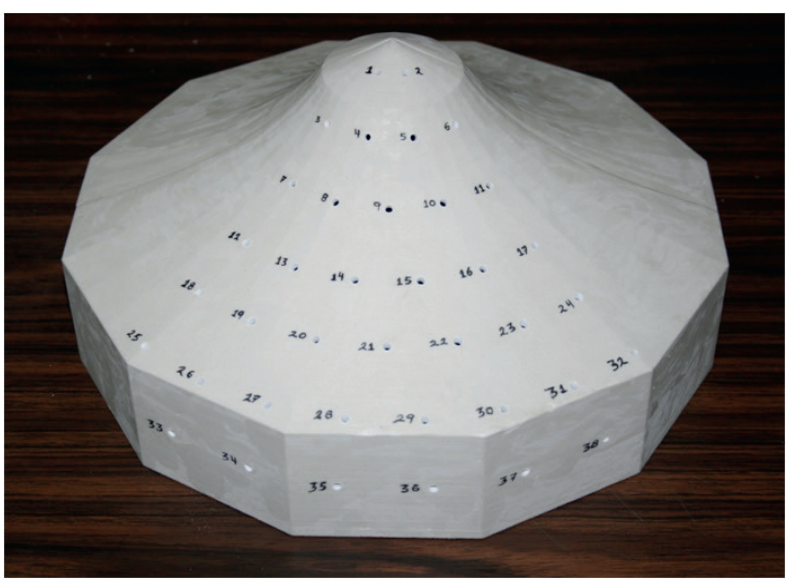

Fig. 6 Scale model and its measurements holes

During the WT tests the model was subjected to laminar flow with 20 and $25 \mathrm{~m} / \mathrm{s}$ velocities. By rotating the model in the wind tunnel, $C_{p}$ values were obtained in 24 points along the horizontal centerline of the walls, in 100 points on the membrane, and in 8 points on the cap. Fig. 7 presents the WT-based $C_{p}$ values on the roof. Due to structure symmetry, one single wind direction was studied.

\subsection{CWE Analysis}

The CWE analysis involved the determination of the $C_{p}$ map on a rigid model applying the Realizable $k-\varepsilon$ and SST $k-\omega$ turbulence models. For each turbulence model, a different mesh was constructed, according to the turbulence model requirements. Due to symmetry, only half of the structure was analyzed. The domain size was set according to the recommended requirements defined in [20]: $5 \mathrm{H}$ for inlet, lateral and top boundaries, and $15 \mathrm{H}$ for outflow boundary, where $\mathrm{H}$ is the height of the model (Fig. 8). Table 2 presents the applied boundary conditions.

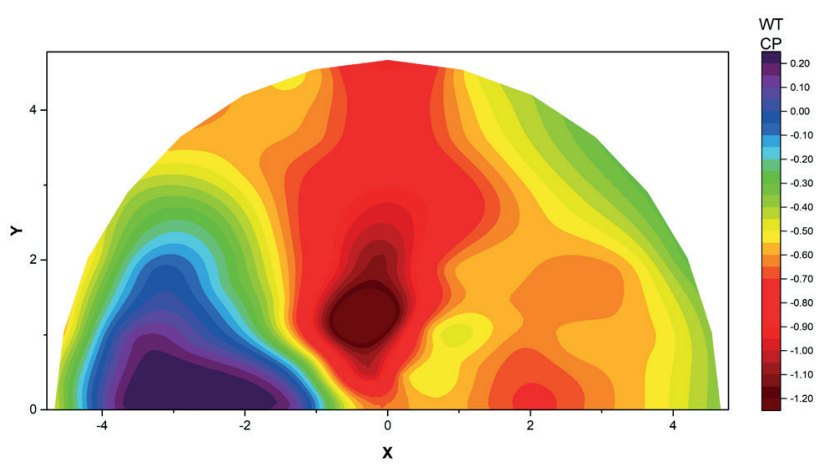

Fig. 7 Experimental pressure coefficients on the membrane surface

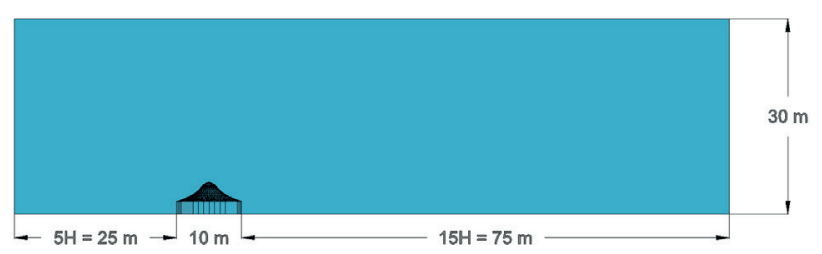

(a)

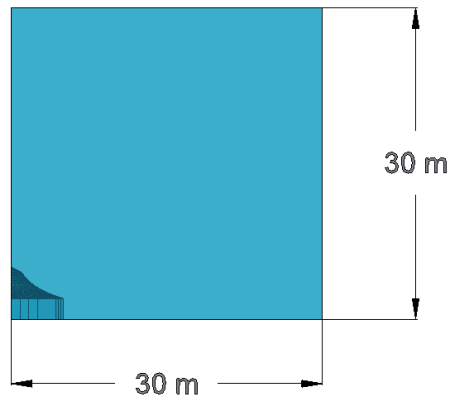

(b)

Fig. 8 Domain dimensions. Lateral view (a) and front view (b) 
Table 2 Boundary conditions for CWE analysis

\begin{tabular}{lc}
\hline Boundary & Condition \\
\hline Inlet & Uniform velocity \\
Outlet & Gauge pressure, 0 Pa \\
Top and lateral & Slip \\
Symmetry plane & Symmetry \\
Walls \& bottom & No-slip wall \\
\hline
\end{tabular}

\subsubsection{Realizable $k-\varepsilon$ turbulence model}

The full-scale structure was analyzed with Realizable $k-\varepsilon$ turbulence model. A fine mesh was constructed on the whole domain, and especially around the model surface where the wind turbulence strongly influences the eddies (Fig. 9). The mesh had approximately 3.5 million quadratictetrahedral elements. For the analysis, scalable wall function was selected because it gives better approach when there are refined parts in the mesh [22]. To guarantee that the dimensionless wall distance $\mathrm{Y}^{+}<11$, required for scalable wall function approach, the first cell height on the model surface was chosen to be $0.15 \mathrm{~mm}$. The face sizing on the membrane surface was chosen to be $0.20 \mathrm{~m}$, while the maximum element size for the whole domain was $1.5 \mathrm{~m}$. The inlet uniform velocity varied between $1 \mathrm{~m} / \mathrm{s}$ and $60 \mathrm{~m} / \mathrm{s}$. Since no significant differences were found between the results, the $C_{p}$ values are presented only for $15 \mathrm{~m} / \mathrm{s}$ velocity. The convergence was achieved in around 2500 iteration steps.

\subsubsection{SST $\boldsymbol{k}$ - $\omega$ turbulence model}

The 1:30 scaled model was analyzed with the SST $k-\omega$ turbulence model to get the best approximation of the WT tests. The applied mesh had approximately 4.8 million elements. The interior of the mesh was composed of hexahedral cells; the areas close to the boundaries contained pyramid and tetrahedral cells. The mesh was refined around the model similarly to the mesh for the Realizable $k-\varepsilon$ model. Uniform $20 \mathrm{~m} / \mathrm{s}$ inlet velocity was applied for the analysis as in the case of the WT test. Stable convergence was achieved in 12000 iteration steps.

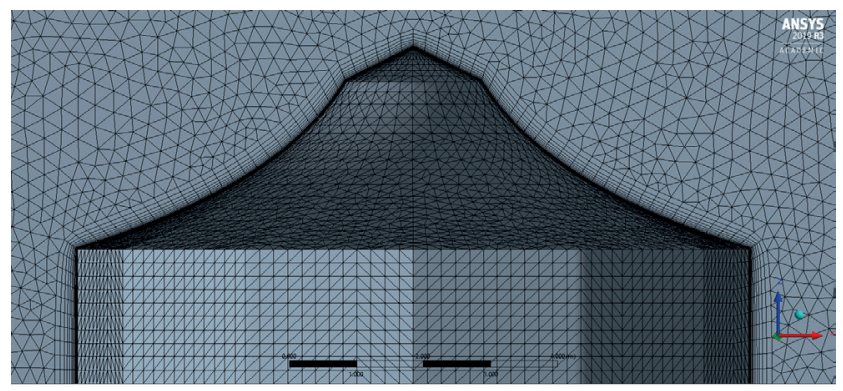

Fig. 9 Mesh for the Realizable $k-\varepsilon$ model, zoomed view

\subsection{Pressure coefficients on the membrane surface}

In the following figures the obtained pressure coefficients on the membrane roof are presented. Fig. 10 depicts the $C_{p}$ values based on the Realizable $k-\varepsilon$ model, while Fig. 11 shows the results of the SST $k-\omega$ model. For an easier comparison of the WT and CWE results, the same color scale is used, as in Fig. 7. The character of the three compared $C_{p}$ fields, the areas of wind pressure and wind suction show a good match.

Fig. 12 gives the pressure coefficients on the walls at the measurement points of the model used for the WT tests (Fig. 6). The CFD results are similar and they are close to the experimental values as well; the most significant differences can be detected at the side of the structure where the wind direction is close to tangential to the wall.

In Fig. 13 the $C_{p}$ values are presented in the vertical symmetry plane of the structure parallel (a) and perpendicular (b) to the wind direction. It can be stated that on the leeward side of the membrane roof all methods provided negative $C_{p}$ values. Along the windward section all methods gave positive $C_{p}$ with the exception of a relatively small area close to the windward edge of the roof (at the top of the front walls). In the section perpendicular to the wind direction, all methods provided negative $C_{p}$ values.

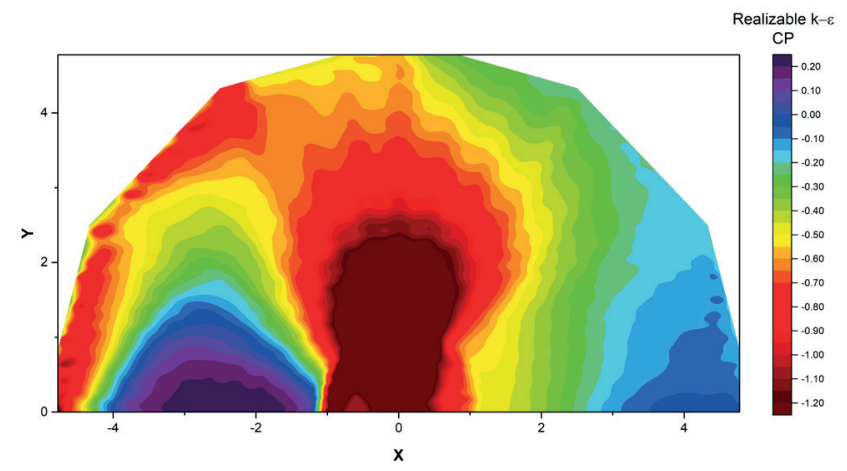

Fig. 10 Pressure coefficients on the membrane surface based on the Realizable $k-\varepsilon$ model

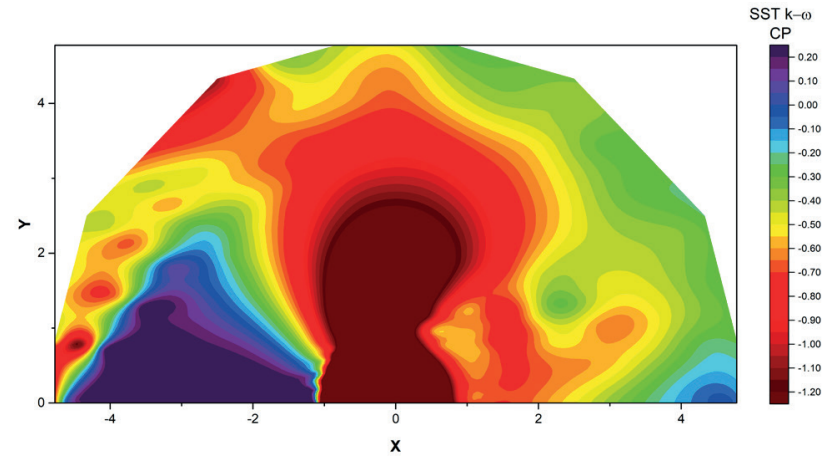

Fig. 11 Pressure coefficients on the membrane surface based on the SST $k-\omega$ model 


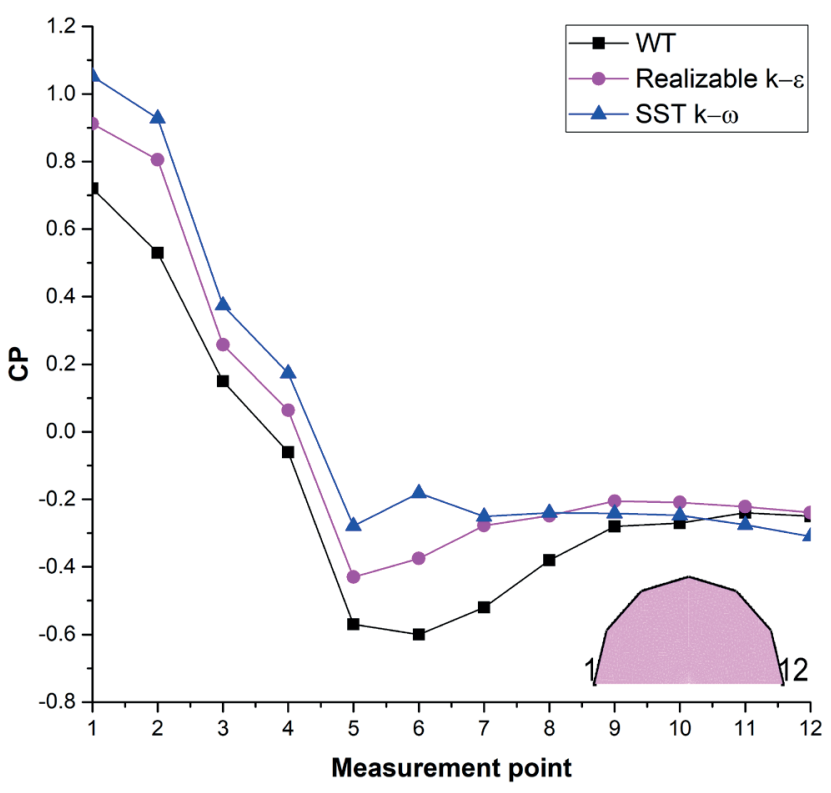

Fig. 12 Pressure coefficients on the vertical walls

Both CWE models provided large negative pressure coefficients at the top of the roof (there were no measurement points in the analyzed symmetry planes on the roof cap in the case of the WT tests.).

\subsection{Membrane forces and displacements}

Since the membrane forces and the displacements are the most important values during the static analysis of membrane structures, their distribution and their significant values based on the different $C_{p}$ fields were also compared. The membrane forces were calculated by the DRM. The following material properties of the membrane

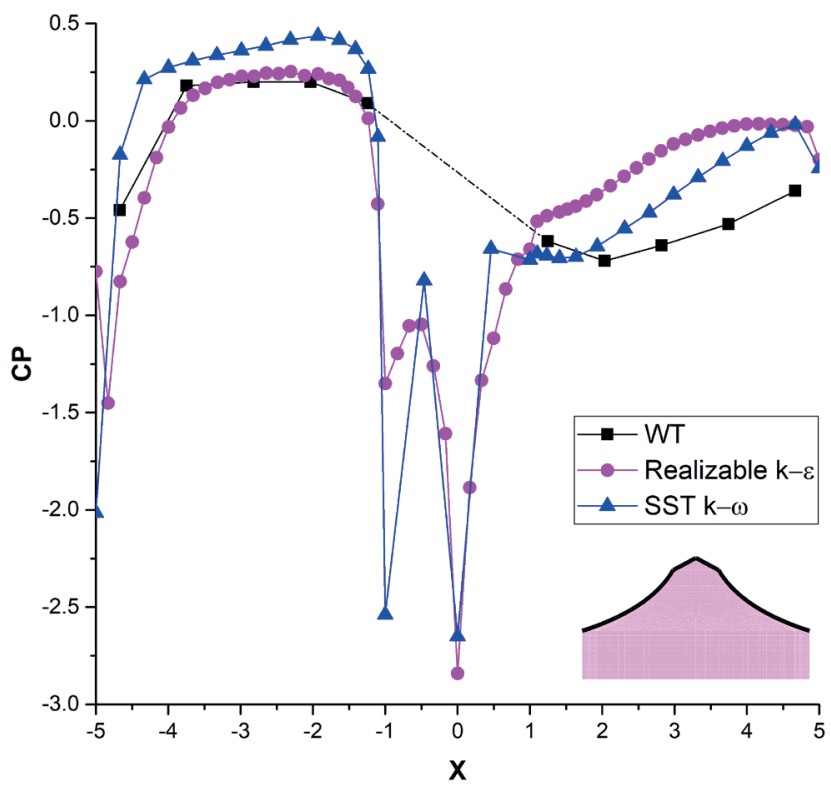

(a) were used: Young's modulus in warp and weft (fill) directions, $E_{\text {warp }}=600 \mathrm{kN} / \mathrm{m}, E_{\text {weft }}=150 \mathrm{kN} / \mathrm{m}$; shear modulus $G=5 \mathrm{kN} / \mathrm{m}$. The fiber directions in the material were calculated in every triangular membrane element on the basis of the cutting pattern [8]. (Warp direction is close to the radial direction.) The membrane forces in the construction shape (in the prestressed membrane without external loads) is presented in Fig. 14.

The membrane forces in the loaded roof were also calculated according to a wind load with $1.2 \mathrm{kN} / \mathrm{m}^{2}$ peak velocity pressure. The membrane forces in warp direction are presented in Figs. 15-17. The maximum value can be detected on the windward side, at the upper supporting ring of the membrane.

The maximum and average values of the membrane forces in warp and weft directions are presented in Table 3. The results show that except for one significant value, the difference between the WT-based and the CWE-based results is less than $10 \%$. The SST $k-\omega$ based maximum membrane force in warp direction overestimates the WT based value by $20 \%$.

Displacements of the membrane in the vertical cross-sections parallel and perpendicular to the wind direction are presented in Figs. 18 and 19, respectively. Additionally, the maximum displacement values, which can be detected in the cross-section perpendicular to the wind direction, are shown in Table 3. Compared to the WT-based results, the maximum displacement is overestimated by about $1 \%$ by the Realizable $k-\varepsilon$ model, and about $12 \%$ by the SST $k-\omega$ model.

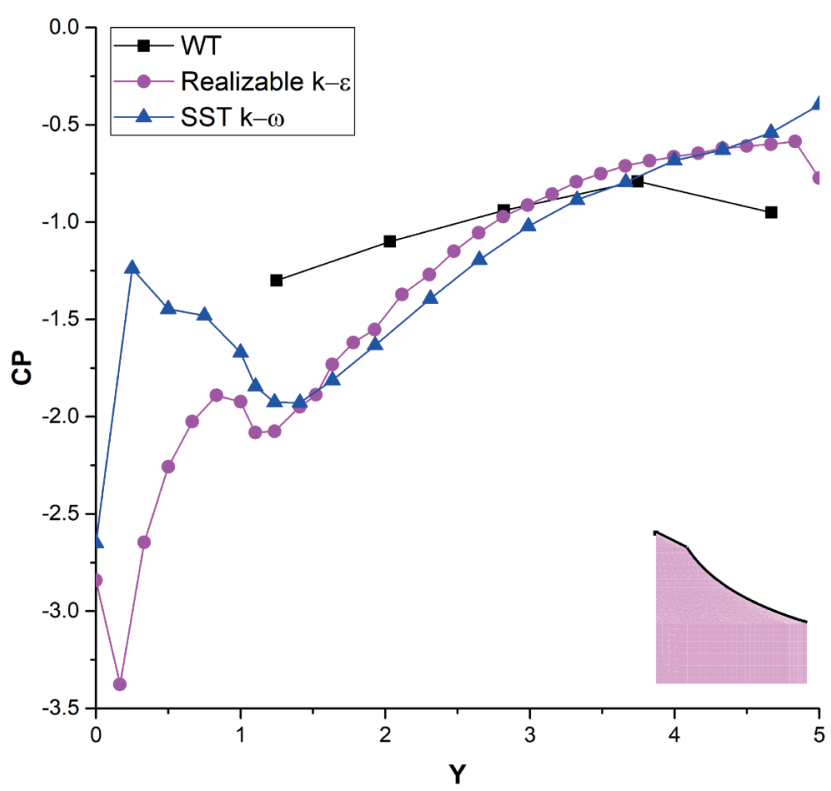

(b)

Fig. 13 Pressure coefficients on the membrane centerline parallel (a) and perpendicular to the wind direction (b) 
Table 3 Membrane forces, displacements, and strain energy comparison

\begin{tabular}{|c|c|c|c|c|c|c|}
\hline & \multicolumn{2}{|c|}{$\begin{array}{c}\text { Membrane } \\
\text { forces, warp } \\
{[\mathrm{kN} / \mathrm{m}]}\end{array}$} & \multicolumn{2}{|c|}{$\begin{array}{c}\text { Membrane } \\
\text { forces, weft } \\
{[\mathrm{kN} / \mathrm{m}]}\end{array}$} & \multirow{2}{*}{$\begin{array}{c}\text { Display- } \\
\text { cement } \\
{[\mathrm{mm}]} \\
\text { Max. }\end{array}$} & \multirow[t]{2}{*}{$\begin{array}{c}\text { Strain } \\
\text { energy } \\
{[\mathrm{kJ}]}\end{array}$} \\
\hline & Max. & Avg. & Max. & Avg. & & \\
\hline $\begin{array}{l}\text { Construction } \\
\text { shape }\end{array}$ & 3.02 & 1.77 & 1.32 & 1.11 & - & 0.35 \\
\hline $\begin{array}{l}\text { Wind load, } \\
\text { WT }\end{array}$ & 9.15 & 2.75 & 5.80 & 3.63 & 277 & 3.77 \\
\hline $\begin{array}{l}\text { Wind load, } \\
\text { CWE, } k-\varepsilon\end{array}$ & 8.44 & 2.92 & 5.26 & 3.54 & 280 & 3.57 \\
\hline $\begin{array}{l}\text { Wind load, } \\
\text { CWE, } k-\omega\end{array}$ & 10.98 & 3.09 & 6.03 & 3.85 & 309 & 4.36 \\
\hline
\end{tabular}

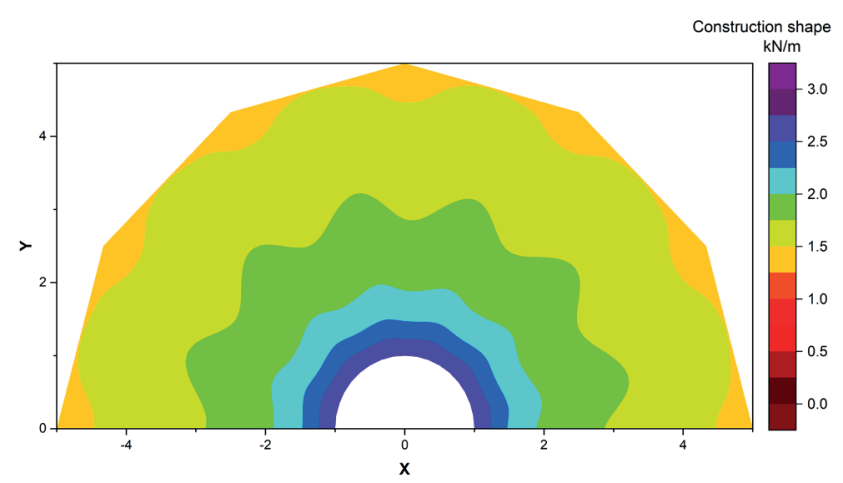

Fig. 14 Membrane forces in the construction shape

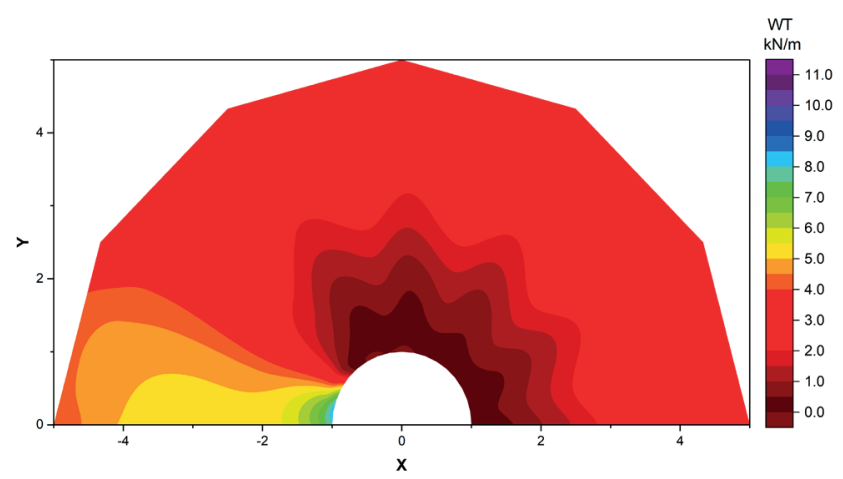

Fig. 15 Membrane forces based on the pressure coefficients obtained by WT

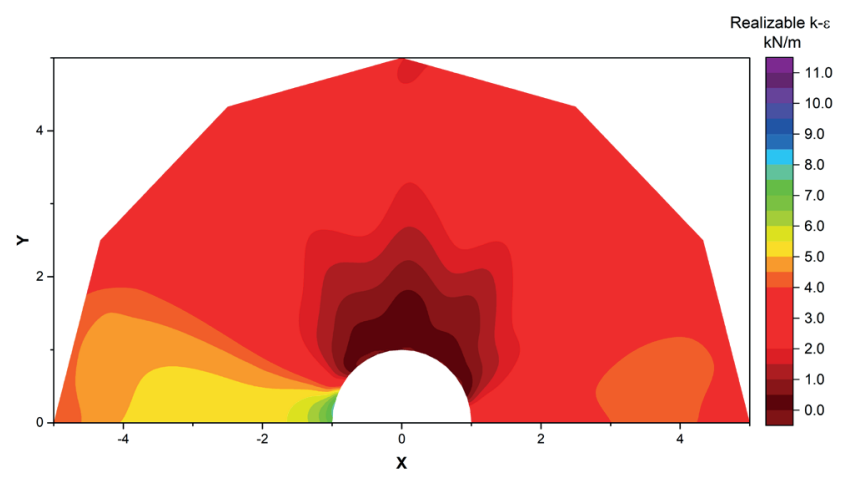

Fig. 16 Membrane forces based on the pressure coefficients obtained by the Realizable $k-\varepsilon$ turbulence model

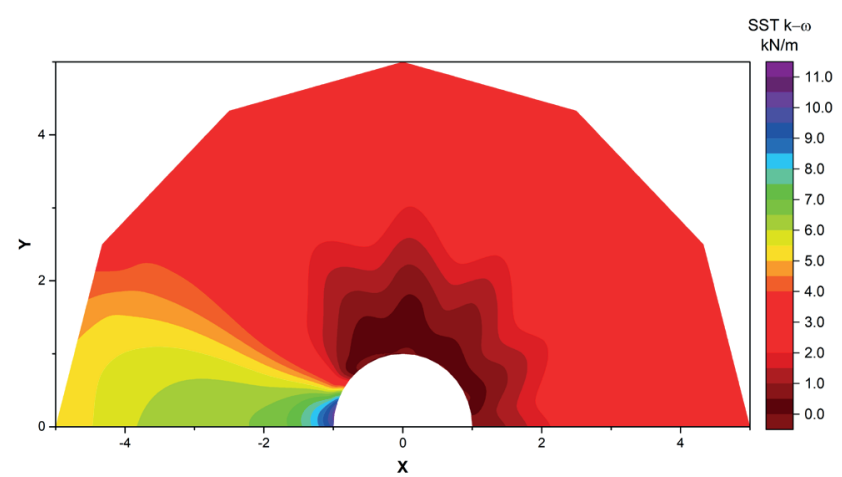

Fig. 17 Membrane forces based on the pressure coefficients obtained by the SST $k-\omega$ turbulence model

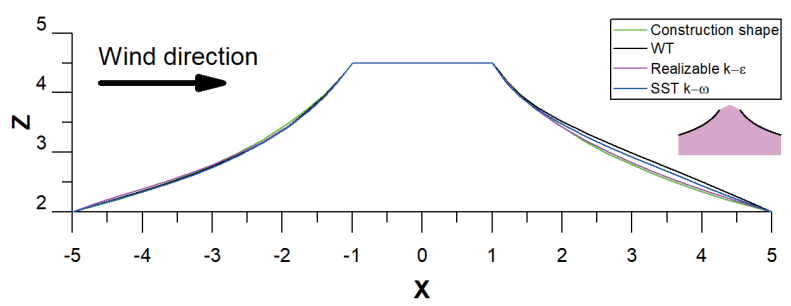

Fig. 18 Membrane displacements along the cross-section parallel to the wind direction

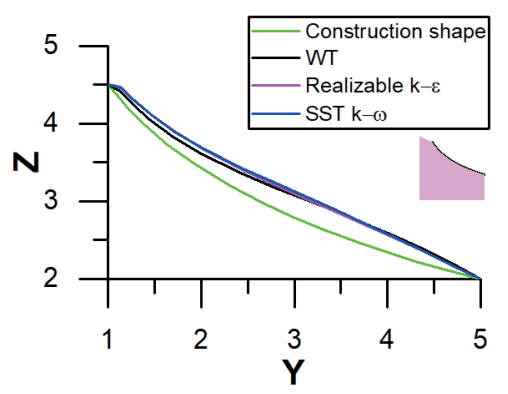

Fig. 19 Membrane displacements along the cross-section perpendicular to the wind direction

Nonetheless, on the leeward side the CFD-based calculations underestimate the displacements.

The strain energy was also calculated for the construction shape and all load cases (Table 3). The strain energy is underestimated by about $5 \%$ by the Realizable $k-\varepsilon$ model and overestimated by about $16 \%$ by the SST $k-\omega$ model, compared to the WT-based results.

\section{Conclusions}

The research aimed to determine the wind pressure coefficients on a hyperbolic membrane roof with the help of CFD analysis. The RANS approach was applied with the Realizable $k-\varepsilon$ and the SST $k-\omega$ turbulence models. As the first step of the model validation, a cube was studied and the results were compared with different experimental and numerical results from the literature. 
In the second step, a mast-supported membrane structure was analyzed, and the CWE results were compared with experimental results.

It can be stated that both turbulence models presented a good approach to the WT-based pressure coefficients for the cube and the membrane structure as well. The nonlinear static analysis of the membrane roof proved that the membrane forces, the displacements, and the strain energy calculated on the basis of the CWE pressure coefficients are a good approximation of the results based on

\section{References}

[1] Lewis, W. J. "Tension Structures: Form and Behaviour", ICE publishing, Westminster, London, 2018.

[2] ASCE "ASCE/SEI 55-16 Tensile Membrane Structures", American Society of Civil Engineers, Reston, VI, USA, 2016. https://doi.org/10.1061/9780784414378

[3] Beccareli, P. "Biaxial Testing for Fabrics and Foils", Springer, Cham, Switzerland, 2015.

https://doi.org/10.1007/978-3-319-02228-4

[4] Hincz, K., Gamboa-Marrufo, M. "Deformed Shape Wind Analysis of Tensile Membrane Structures", ASCE Journal of Structural Engineering, 142(3), Article number: 04015153, 2015. https://doi.org/10.1061/(ASCE)ST.1943-541X.0001437

[5] Seidel, M. "Tensile Surface Structures. A Practical Guide to Cable and Membrane Construction: Materials, Design, Assembly and Erection", Ernst \& Sohn, Berlin, Germany, 2009. https://doi.org/10.1002/9783433600269

[6] Kröplin, B. "Inflated Membrane Structures on the Ground, in the Air and in Space - A Classification", In: Oñate, E., Kröplin, B. (eds.) Textile Composites and Inflatable Structures, Springer, Dordrecht, The Netherlands, 2005, pp. 213-220. https://doi.org/10.1007/1-4020-3317-6_13

[7] Wagner, R. "On the Design Process of Tensile Structures", In: Oñate, E., Kröplin, B. (eds.) Textile Composites and Inflatable Structures, Springer, Dordrecht, The Netherlands, 2005, pp. 1-16. https://doi.org/10.1007/1-4020-3317-6_1

[8] Hincz, K. "Determination of the cutting pattern of prestressed tent structures", Revista Portuguesa de Engenharia de Estruturas, 47, pp. 45-49, 2000.

[9] Gamboa-Marrufo, M., Hincz, K., Tun Cruz, V. "Medición de presiones aerodinámicas en una estructura de membrana" (Wind pressure measurements on a membrane structure), Ingeniería Revista Académica de la Facultad de Ingeniería, Universidad Autónoma de Yucatán, 15 (3), pp. 167-175, 2011. (in Spanish)

[10] Simiu, E., Yeo, D. "Wind Effects on Structures: Modern Structural Design for Wind, Fourth Edition", Wiley Blackwell, Singapore, 2019.

https://doi.org/10.1002/9781119375890

[11] CFE "Manual de diseño de obras civiles: diseño por viento" (Manual of Civil Structures: wind design), Comisión Federal de Electricidad, Mexico City, Mexico, 2020. (in Spanish) the experimental $C_{p}$ values. The results show that after thorough validation, CWE can be an efficient tool for the determination of the wind load on membrane structures.

\section{Acknowledgement}

This work was supported by NKFI (Grant K138615, Grant TKP2020 NC and Grant No. BME-NCS) and VEKOP-2.3.3-15-2017-00017 project "Establishment of an Atmospheric Flow Laboratory".

[12] Gamboa-Marrufo, M., Rosado-Hau, N., Pacheco-Pacheco, A. "Validación mediante CFD de los coeficientes de presión de una tenso estructura obtenidos en un túnel de viento" (CFD validation of pressure coefficients of a tensile structure obtained with wind tunnel tests), Revista Académica de la Facultad de Ingeniería, Universidad Autónoma de Yucatán, 17(3), pp. 215-222, 2013. (in Spanish) [online] Available at: https://www.redalyc.org/articulo. oa? id $=46730914005$

[13] Sun, X., Arjun, K., Wu, Y. "Investigation on wind tunnel experiment of oval-shaped arch-supported membrane structures", Journal of Wind Engineering and Industrial Aerodynamics, 206, Article number: $104371,2020$. https://doi.org/10.1016/j.jweia.2020.104371

[14] Richards, P. J., Hoxey, R. P., Short, L. J. "Wind pressures on a $6 \mathrm{~m}$ cube", Journal of Wind Engineering and Industrial Aerodynamics, 89(14-15), pp. 1553-1564, 2001. https://doi.org/10.1016/S0167-6105(01)00139-8

[15] Richards, P. J., Hoxey, R. P., Connel, B. D., Lander, D. P. "Windtunnel modelling of Silsoe Cube", Journal of Wind Engineering and Industrial Aerodynamics, 95 (9-11), pp. 1384-1399, 2007. https://doi.org/10.1016/j.jweia.2007.02.005

[16] Richards, P. J. Hoxey, R. P. "Wind loads on the roof of a $6 \mathrm{~m}$ cube", Journal of Wind Engineering and Industrial Aerodynamics, 96(6-7), pp. 984-993, 2008. https://doi.org/10.1016/j.jweia.2007.06.032

[17] Castro, I. P., Robins, A. G. "The flow around a surface-mounted cube in uniform and turbulent streams", Journal of Fluid Mechanics, 79(2), pp. 307-335, 1977. https://doi.org/10.1017/S0022112077000172

[18] Irtaza, H., Beale, R. G., Godley, M. H. R., Jameel, A. "Comparison of wind pressure measurements on Silsoe experimental building from full-scale observation, wind-tunnel experiments and various CFD techniques", International Journal of Engineering, Science and Technology, 5(1), pp. 28-41, 2013. https://doi.org/10.4314/ijest.v5i1.3

[19] Amaya-Gallardo, E., Pozos-Estrada, A., Gómez-Martínez, R. "Simulación experimental y numérica para la obtención de coeficientes de presión sobre un cubo: estudio comparativo" (Experimental and numerical simulation to obtain pressure coefficients on a cube: comparative analysis), presented at XX Congreso Nacional de Ingeniería Estructural, Mérida, Yucatán, México, Nov, 16-19, 2016. (in Spanish) 
[20] Franke, J., Hellsten, A., Schlünzen, H., Carissimo, B. (eds.) "Best practice guideline for the CFD simulation of flows in the urban environment, Quality Assurance and Improvement of Microscale Meteorological Models", COST Action 732, Hamburg, Germany, 2007.[online]Availableat:https://www.researchgate.net/publication/ 257762102
[21] ASCE "ASCE/SEI 7-16 Minimum Design Loads for Buildings and Other Structures", American Society of Civil Engineers, Reston, VA, USA, 2016. https://doi.org/10.1061/9780784412916

[22] ANSYS Inc. "ANSYS Fluent theory guide", [online] Available at: https://www.ansys.com/ 